\title{
THE ART OF THE POSSIBLE: EXPERIENCE AND PRACTICE IN HEALTH IMPACT ASSESSMENT IN NEW SOUTH WALES
}

\author{
Stephen Corbett \\ Centre for Population Health \\ Sydney West Area Health Service
}

Richard Seymour was appointed the first Inspector of Nuisances in Sydney in 1884. His work approving and inspecting opium dens, privies, abattoirs and tanneries contained many of the elements we now call health impact assessment (HIA). Indeed the entire corpus of planning and environmental protection legislation and the building codes have encoded provisions which are a distillation of the accumulated wisdom and prejudice formed in doing these assessments. In this article I have attempted to distil some of the lessons learned in the commissioning and conduct of environmental health impact assessments in NSW since 1990, in the hope that some of these at least will be of direct relevance to the conduct of HIA in other settings.

Officers within state and local government have long been asked for their views about the potential impacts of all types of development. These opinions became a de facto part of a legislative process with the passage of the NSW Environmental Planning and Assessment Act in 1979. Health advice was regularly sought in relation to air and water quality issues and chemical and physical hazards such as noise, radiation and odour.

Tasmania is the only state in Australia where health impact assessment (HIA) is mandated for certain categories of development under planning legislation. It is not clear if this step is necessary or even desirable. In other states environmental impact assessments (EIAs) have become increasingly complex and costly procedures done by specialised companies that can draw on vast technical expertise. If specified appropriately, EIAs can improve the integration of health goals into planning decisions and achieve greater transparency and public involvement. Critics of EIA have pointed to this complexity, to limited and adversarial public participation, and to the emphasis on procedure over substance as arguments against the effectiveness of EIA and, by analogy, HIA. ${ }^{1}$

A number of large infrastructure projects in NSW have attracted forceful community opposition on health grounds. This is not new. In Sydney between 1910 and 1930 there was intense opposition to the building of the sewer system because of fears about the health effects of sewer gas. ${ }^{2}$ Some of the projects in NSW over the past 15 years involving complex health risk assessments are listed in Box 1. The potential for health issues to become the focus if not the substance of opposition to major infrastructure projects ${ }^{3,4}$ has in recent times triggered consultation among the proposing agencies within government.

HIAs done in the context of an EIA to this point have focussed on the real and present dangers of microbial contamination and noise, and on air and water quality.
Increasingly it has been possible in projects such as the Lane Cove and proposed M4 tunnel, and the Port Botany expansion, to consider a broader range of impacts on public and active transport, community connectivity, open space utilisation, physical activity and access to services.

HIA holds great promise ${ }^{5}$ to enhance recognition of social and environmental determinants of health and to engage health and other professionals and the community in transparent dialogues about the broad health impacts of government policy. But there are also potential pitfalls ${ }^{5}$ : a misplaced emphasis on sins of commission rather omission, a false implication that health is the only or pre-eminent consideration in policy making, the potential to become red tape rather than a genuine participatory exercise, and cost.

In Australia there is a wealth of experience in the practice of environmental HIA but there are a number of lessons to be learned which are equally applicable to HIAs not linked to the built environment.

\section{Trust}

In the absence of mandated impact assessments, trust is crucial to successful collaboration within government. ${ }^{6}$ There are two important dimensions of trust. One is between the agencies of government at officer, executive and ministerial levels. The other is between agencies and community. Both need to be built and maintained through partnerships, communication and responsiveness.

\section{Fidelity to technical merits}

EIAs and HIAs are essentially technical documents that should establish an information base upon which to make

\section{BOX 1}

SOME MAJOR PROJECTS INVOLVING DETAILED HEALTH RISK ASSESSMENT IN NSW, 1990-2005

3rd runway at Sydney Airport

Eastern distributor

Rhodes peninsula rehabilitation and development

Botany groundwater contamination

Cross city tunnel

Medical waste treatment facility, Newcastle

2nd airport proposal at Badgery's Creek

M5 East tunnel and stack

Northside storage (sewerage) tunnel

Western Sydney orbital

Lane Cove tunnel

Hexachlorbenzene and Geomelt disposal technology

Reopening of the copper smelter in Port Kembla

Picnic Point to Haymarket $330 \mathrm{kV}$ line 
informed choices. There are real challenges both for health professionals and the public in accepting the validity of some of this information. For example, air quality modeling, which is now well established as the basis for decision making in relation to air pollution control, is for most health professionals a black box. ${ }^{7}$ If we expect the community to accept the results of HIAs and to maintain fidelity to the technical merits of scientific arguments then there is an obligation to define and produce information that is comprehensible and meaningful.

\section{Learning by doing}

EIA or HIA can and should be used to demonstrate how the benefits of a proposal or policy can be maximised. Modifications can sometimes be achieved with surprising ease. The Picnic Point to Haymarket $330 \mathrm{kV}$ cable was proposed to improve energy security for the Sydney central business district. Residents living close to the proposed route expressed concerns about exposure to electromagnetic fields. After an HIA, field strength was able to be halved using several mitigation strategies, including moving the cables closer together.

\section{Costs and benefits}

The cost of modifications to large projects can be high. A recent assessment of the relative costs of three options for the configuration of an overhead electricity cable, each conferring a small difference in field strength at ground level, was presented to government. ${ }^{8}$ Cost differentials were in excess of $\$ 30$ million.

Large infrastructure projects in NSW are defined as those which cost more than $\$ 100$ million. If health issues threaten to jeopardise the acceptability and final approval of the project or policy then the acceptable costs of modifications will rise accordingly. It is often difficult to assess the validity of the costs the proponent ascribes to suggested project modifications. Recently a number of proponents have commissioned independent costings of design options, and this does assist decision making.

\section{CONCLUSION}

There is an art in conducting HIAs, an art of the possible, and much is to be learned by doing. Experience has shown that the scope of admissible health issues can broaden over time, just as it has with environmental issues in EIA. For example, as the evidence linking transport choice and levels of activity grows it should be possible to distill these findings into firm requirements for transport developments.

The rehabilitation of highly contaminated foreshores on the Rhodes Peninsula is a good example of an HIA done in collaboration with all arms of government and with the community. A summary is provided in Box 2.

The Centers for Disease Control Agency for Toxic Substances and Disease Register maintains an information

\section{BOX 2}

\section{HEALTH IMPACT ASSESSMENT ON THE RHODES PENINSULA REDEVELOPMENT}

The Rhodes Peninsula and adjacent parts of Homebush Bay have had significant dioxin contamination from previous industrial activity. The proposal to clean the land and bay sediments to allow residential redevelopment of the peninsula required use of HIA from two perspectives:

\section{Suitability of the site for future residents}

This included describing potential activities that may affect dioxin exposure, such as contact with bay sediments when wading or boating, ingestion of bay water during boating or swimming, and access to residual contamination in soils around the medium density development. Once the range, frequency and likelihood of such activities was established then potential exposure to dioxin was able to be estimated, and appropriate clean-up goals, or restrictions to access, recommended.

\section{Impact of the remediation on existing residents}

The contaminated site, where the full remediation process is to occur, is separated by less than 100 metres from the nearest existing residents. The HIA had to consider potential exposure of current residents to air emissions from the treatment plants, offsite spread of disturbed contaminated sediments and soil, and noise from the excavation and treatment processes. Uses of the residential sites on the peninsula could include growing vegetables, keeping poultry and children playing in soil, and these uses could influence exposure to contaminated air and dust spread from the site. The HIA was able to identify the key risks for human exposure to these hazards and recommend where controls should be placed to reduce this risk, and a monitoring regime to check on the control strategies. The HIA also identified that with appropriate control strategies in place the risk from the remediation to existing residents was low, and feedback and reassurance to the community was able to be provided.

base $^{9}$ on public health investigations in the United States. The World Health Organizatioin maintains an international website for HIA. There may be value in extracting from these sources a compilation of national experience in conducting these assessments as a guide for practitioners in this emerging discipline in Australia. 


\section{ACKNOWLEDGEMENTS}

I would like to acknowledge the comments and additions suggested by members of the Environmental Health Branch, NSW Health, and by journal reviewers.

\section{REFERENCES}

1. Cole BL, Wilhelm M, Long PV, Fielding JE, Kominski G, Morgenstern H. Prospects for health impact assessment in the United States: New and improved environmental impact assessment or something different? Journal of Health Politics, Policy \& Law 2004; 29(6): 1153-86.

2. Beder S. Early environmentalists and the battle against sewers in Sydney, Royal Australian Historical Society Journal 1990; 76(1): 27-44.

3. Legislative Council. General Purpose Standing Committee. Report on Inquiry into Northside Storage Tunnel-Scotts Creek Vent. Parliamentary paper No. 453, 2000.

4. Legislative Council. General Purpose Standing Committee No. 5. Inquiry into the M5 East Tunnel. Sydney: New South Wales Parliament, 2002.
5. Krieger N, Northridge M, Gruskin S, Quinn M, Kriebel D, Davey Smith G, et al. Assessing health impact assessment: Multidisciplinary and international perspectives. J Epidemiol and Community Health 2003; 57: 659-62.

6. Hunter D. Ch 2: The relationship between health and health care. In Public Health Policy. Polity Press, 2003.

7. Landy MK, Roberts MJ, Thomas SR. The Environmental Protection Agency: Asking the wrong questions from Nixon to Clinton. New York: Oxford University Press, 1994.

8. Vineyard to Rouse Hill electricity upgrade-Independent report to examine the cost of the options for the upgrade. November 2004. Maunsell Australia Pty Ltd. Available from the Integral energy website at: www.integral.com.au/index. cfm?objectid=B05033AF-8028-BBAF-106908876245FC3A. Accessed 9 November 2005.

9. Agency for Toxic Substances and Disease Register. Public Health Assessments. Available at www.atsdr.cdc.gov/HAC/ PHA/, accessed 9 November 2005. 용

\section{BUILDING AN EQUITY FOCUS IN HEALTH IMPACT ASSESSMENT}

\author{
Rosemary Aldrich \\ Newcastle Institute of Public Health \\ University of Newcastle
}

\section{Mary Mahoney \\ Health Impact Assessment Research Unit \\ Deakin University, Melbourne}

Elizabeth Harris and Sarah Simpson*

Centre for Health Equity Training Research

and Evaluation

University of New South Wales

\section{Jenny Stewart-Williams}

Newcastle Institute of Public Health

University of Newcastle

Health impact assessment (HIA) is underpinned by equity as a core value in its conventions and objectives. ${ }^{1}$ However, there has been debate on whether an explicit assessment of impacts on health inequalities is required to characterise the differential distribution of impacts on health that might result from a policy, planning or service decision. The Jakarta Declaration ${ }^{2}$ and the United Kingdom's Independent Inquiry into Inequalities in Health ${ }^{3}$ called for equity-focused HIA and health inequalities impact assessment respectively (reiterated in the Bangkok Charter on Health Promotion in a Globalised World ${ }^{4}$ ). Attendees at a methodological seminar in 2001 in the United Kingdom assembled to discuss this issue decided, however, not to

\footnotetext{
* Sarah Simpson is currently employed by the World Health Organization in Geneva as Coordinator, Knowledge Networks, Commission on the Social Determinants of Health
}

differentiate health inequalities impact assessment from health impact assessment, instead concluding that every HIA should be a health inequalities impact assessment. ${ }^{5}$ Here we describe the development of a framework to guide equity-focussed HIA. Although the terms 'equity-focussed HIA' and 'health inequalities impact assessment' have been used synonymously in the literature, our collaboration used the term 'equity-focussed health impact assessment' instead of 'health inequalities impact assessment' as we wished to communicate that assessment of equity impacts was integral to HIA instead of a different process.

A review of 30 reports in the literature describing HIAs found that in practice few had explored equity impacts routinely or systematically, although some tools for health inequalities impact assessment had emerged. ${ }^{6}$ This reinforced our commitment to develop and pilot a framework for equity-focused health impact assessment that could be integral to the HIA, and used to explicitly consider the impacts on health inequalities that may result from a policy, plan or program.

In 2002, building on our work to develop policy-linked $\mathrm{HIA}^{7}$ and also on using socioeconomic evidence in health decision-making ${ }^{8}$, researchers from the Newcastle Institute of Public Health (NIPH), the Centre for Health Equity Training, Research and Evaluation (CHETRE) and the Health Impact Assessment Research Unit at Deakin University established the Australasian Collaboration for Health Equity Impact Assessment (ACHEIA). Together with our case-study partners and international advisors from the Cochrane and Campbell Collaborations and from 